Check for updates

Cite this: RSC Adv., 2019, 9, 32594

Received 21st August 2019 Accepted 7th October 2019

DOI: $10.1039 / c 9 r a 06562 h$

rsc.li/rsc-advances

\section{Mechanism and kinetics of the atmospheric reaction of 1,3,5-trimethylbenzene bicyclic peroxy radical with $\mathrm{OH} \dagger$}

\begin{abstract}
Xiaoxiao Lin, ${ }^{a}$ Zhenli Yang, ${ }^{\text {ab }}$ Hui Yu, ${ }^{\text {ab }}$ Yanbo Gai ${ }^{\text {*a }}{ }^{\star a}$ and Weijun Zhang ${ }^{\text {*a }}$
The bicyclic peroxy radical (BPR) is the key intermediate during atmospheric oxidation of aromatics. In this paper, the reaction mechanisms and kinetics of the atmospheric reaction of the 1,3,5-trimethylbenzene (1,3,5-TMB) BPR with the $\mathrm{OH}$ radical were studied by density functional theory (DFT) and conventional transition-state theory (CTST) calculations. The product channels of formation of the 1,3,5-TMB trioxide $(\mathrm{ROOOH}), \mathrm{OH}$-adducts and Criegee intermediate $(\mathrm{Cl})$ have been identified, and the geometries and energies of all the stationary points were calculated at the M08-HX/6-311 + g(2df,2p) level of theory. In addition, the rate constants for the individual reaction pathway at $298 \mathrm{~K}$ were calculated. The results showed that $\mathrm{OH}$ addition reactions including the formation of $\mathrm{ROOOH}$ and $\mathrm{OH}$-adducts are the main pathways, whereas Criegee intermediate formation is of minor importance.
\end{abstract}

\section{Introduction}

Aromatics constitute an important fraction (20-40\%) of the total non-methane hydrocarbons (NMHCs) in the urban atmosphere which are mostly emitted by fuel combustion and industrial solvent evaporation. ${ }^{1-3}$ 1,3,5-Trimethylbenzene is a significant component of the suite of aromatic hydrocarbons that leads to the production of tropospheric ozone and secondary organic aerosols (SOA). ${ }^{4}$ Atmospheric oxidation of 1,3,5-trimethylbenzene is mainly initiated by the $\mathrm{OH}$ radical, and the bicyclic peroxy radical (BPR) is the key intermediate during the oxidation. ${ }^{5}$ The detailed gas-phase chemical processes including the degradation mechanism of 1,3,5-trimethylbenzene can be described by MCMv3.1 which is the Master Chemical Mechanism version 3.1. As shown in Scheme 1 , in the $\mathrm{OH}$-initiated oxidation of 1,3,5-trimethylbenzene (TMB), the yields of the initial products formed after the $\mathrm{OH}$ addition to the aromatic ring in MCMv3.1 are 0.79 for the 1,3,5TMB bicyclic peroxy radical (BPR) which have been detected experimentally.,

The main chemical fate of the bicyclic peroxy radical (BPR) depends on levels of $\mathrm{NO} x\left(\mathrm{NO} x=\mathrm{NO}_{2}+\mathrm{NO}\right)$. The major pathway is the reaction with NO in polluted urban areas, which is responsible for tropospheric ozone production. ${ }^{7}$ While in low NOx conditions, the reaction with $\mathrm{HO}_{2}$ or with other peroxy

${ }^{a}$ Laboratory of Atmospheric Physico-Chemistry, Anhui Institute of Optics and Fine Mechanics, Chinese Academy of Sciences, Hefei, 230031, Anhui, China. E-mail: gaiyanbo@aiofm.ac.cn; wjzhang@aiofm.ac.cn

${ }^{b}$ University of Science and Technology of China, Hefei, 230026, Anhui, China

$\dagger$ Electronic supplementary information (ESI) available. See DOI: 10.1039/c9ra06562h radicals plays a larger role. ${ }^{8,9}$ Recently, the reaction with $\mathrm{OH}$ radicals in clean environments has been considered another important loss path. Indeed, the rate constants for the reactions of the $\mathrm{C}_{1}-\mathrm{C}_{4}$ aliphatic peroxy radicals and $\mathrm{OH}$ radicals have been measured experimentally. ${ }^{\mathbf{1 0 - 1 4}}$ The very high rate constants show that the reaction with $\mathrm{OH}$ can be competitive to other reaction paths for peroxy radicals. ${ }^{15,16}$ Both theoretical and experimental studies of alkylperoxy radicals and $\mathrm{OH}$ reactions have shown that the main reaction channel is formation of $\mathrm{ROOOH}$ while the $\mathrm{H}$-abstraction channel giving Criegee intermediate is to be of minor importance. ${ }^{14,17,18}$ However, the mechanism and kinetics for the reactions of aromatic peroxy radicals with $\mathrm{OH}$ radical are still unknown. Due to the effect of $\mathrm{O}_{2}$-bridged bicyclic group substituent, the reactivity of aromatic peroxy radicals toward $\mathrm{OH}$ radical may be different. In this article, we apply density functional theory (DFT) and conventional transition-state theory (CTST) to investigate the reaction mechanisms and kinetics of the 1,3,5-TMB bicyclic peroxy radical (BPR) with $\mathrm{OH}$ radical.

\section{Computational details}

Modern quantum chemical calculations can obtain quantitative kinetics of atmospheric reactions, ${ }^{19-21}$ where quantitative accurate barrier heights are very key for obtaining quantitative rate constants. However, for the large and complex diradical reactions, it's particularly difficult to obtain quantitative barrier heights based on couple cluster theory. For example, the highly accurate $\operatorname{CCSD}(\mathrm{T})$ and $\mathrm{CBS}$ level can not obtain the quantitative barrier heights in the small-sized reaction of the simplest Criegee intermediate $\left(\mathrm{CH}_{2} \mathrm{O}_{2}\right)$ with $\mathrm{H}_{2} \mathrm{O} .{ }^{19}$ Although post$\operatorname{CCSD}(\mathrm{T})$ level of theory is able to deal with such radical- 


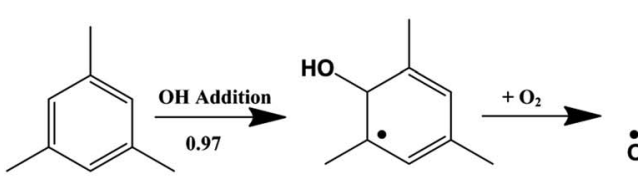

$(1,3,5-T M B)$

(TMB-1)

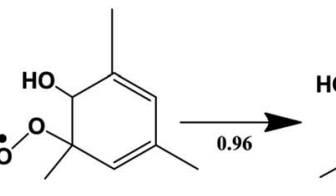

(TMB-2)

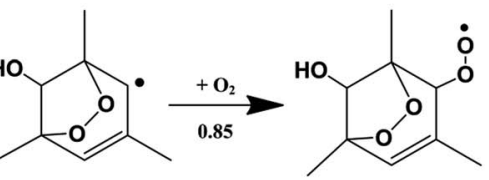

(TMB-3)

(BPR) radical system, the computational costs are prohibitive. In contrast, the density functional theory (DFT) is the commonly used method in theoretical study on atmospheric oxidation of aromatic compounds. ${ }^{22-24}$ M08-HX hybrid functional shows excellent performance for thermochemistry, kinetics, noncovalent interactions. ${ }^{25} \mathrm{Xu}$ et al. carried out extensive systematic study on 48 transition state geometries of small reactions with a variety of methods. ${ }^{26}$ It was found that M08-HX is the most highly recommended functional having a lower cost when compared to doubly hybrid functionals. Moreover, this method has been confirmed reliable by investigation of the small diradical reaction of $\mathrm{CH}_{3} \mathrm{O}_{2}$ and $\mathrm{OH}$. The kinetic results show good agreement with the experimental values (see ESI $\dagger$ for details).

Thus, all stationary points including the reactants, reactant complexes, transition states and products on the potential energy surface of 1,3,5-TMB BPR + OH reaction have been fully optimized by the M08-HX functional with the 6-311 $+\mathrm{g}(2 \mathrm{df}, 2 \mathrm{p})$ basis set. Harmonic vibrational frequency computations were carried out at the same level in order to characterize the nature of the stationary points as either minima (all positive frequencies) or transition states (one and only one imaginary frequency), to provide the zero-point energies (ZPEs), and the thermodynamic contributions to the enthalpy and free energy. Besides, the intrinsic reaction coordinate (IRC) ${ }^{27,28}$ calculations were performed to ensure that the transition states connect the relevant reactants and products. The electronic structure and energy computations were carried out using the Gaussian 16 package. ${ }^{29}$ The rate constants were calculated by conventional transition-state theory (CTST) ${ }^{30-32}$ with the Eckart tunneling correction $^{33}$ using the TheRate program..$^{34,35}$

\section{Results and discussion}

The 1,3,5-TMB bicyclic peroxy radical can undergo both $\mathrm{OH}-$ addition and $\mathrm{H}$-abstraction reactions. As shown in Scheme 2, the addition of $\mathrm{OH}$ radical to the terminal oxygen atom of the bicyclic peroxy radical forms a trioxide (ROOOH). Assaf et al. ${ }^{36}$ suggested that for larger peroxy radicals with more than two or three $\mathrm{C}$-atoms, the trioxide $(\mathrm{ROOOH})$ intermediates undergo mostly colliosional stabilization. Thus the $\mathrm{ROOOH}$ produced by $\mathrm{OH}$ addition on 1,3,5-TMB bicyclic peroxy radical is considered stabilized by collisional energy loss instead of prompt unimolecular reactions at atmospheric conditions. Different from the alkylperoxy radicals, there is a $\mathrm{C}=\mathrm{C}$ double bond on the ring structure of the 1,3,5-TMB bicyclic peroxy radical. Thus the addition of the $\mathrm{OH}$ radical to the double bond to form $\mathrm{OH}$ - adduct may also occur in the title reaction. In addition, the title reaction can be initiated through $\mathrm{H}$-abstraction by $\mathrm{OH}$ radical to give Criegee intermediates which are mainly formed from the ozonolysis reaction of unsaturated substances ${ }^{37,38}$ due to the presence of $\mathrm{CH}$ group adjacent to the $-\mathrm{OO}^{\bullet}$ radical as shown in Scheme 3.

The schematic energy diagrams obtained at M08-HX/6-311+ $\mathrm{g}(2 \mathrm{df}, 2 \mathrm{p})$ level of theory are displayed in Fig. 1 . The most relevant geometrical parameters of all stationary points described in Fig. 1 have been drawn in Fig. 2. Table 1 presents the thermodynamic parameters including the relative energies $(\Delta(E+$ ZPE) and $\left.\Delta E_{298 \mathrm{~K}}\right)$, enthalpies $\left(\Delta H_{298 \mathrm{~K}}\right)$, and Gibbs free energies $\left(\Delta G_{298 \mathrm{~K}}\right)$. Then CTST rate constants of each channel at $298 \mathrm{~K}$ are listed in Table 2.

\subsection{Trioxide formation between 1,3,5-TMB BPR and $\mathrm{OH}$}

The important reaction between 1,3,5-TMB BPR and OH radical is addition of $\mathrm{OH}$ to the terminal oxygen atom of the peroxy end to produce $\mathrm{ROOOH}$ shown in Scheme 3. The large aromatic $\mathrm{ROOOH}$ is stabilized as Assaf et al. ${ }^{36}$ predicted that the trioxide, $\mathrm{ROOOH}$ containing more than three carbons are nearly exclusively collisionally stabilized in atmospheric conditions. This reaction starts with a $\mathrm{H}$-bonded reactant complex ${ }^{1} \mathrm{RC} 1$ which is $4.14 \mathrm{kcal} \mathrm{mol}^{-1}$ stabilized with respect to the separated reactants before the transition state ${ }^{1}$ TSA and the corresponding product $\mathrm{ROOOH}$, which is clearly displayed in Fig. 1. The structures of key species of the title reaction on the potential energy surface have been drawn in Fig. 2. In ${ }^{1} \mathrm{RC} 1$ (see Fig. 2), the $\mathrm{O} \cdots \mathrm{HO}$ bonding occurs between the terminal $\mathrm{O}$ atom of BPR and the $\mathrm{H}$ atom of $\mathrm{OH}$ radical with the distance of $2.013 \AA$. In ${ }^{1}$ TSA, the vibration mode of the imaginary frequency shows reorientation of $\mathrm{OH}$ fragment and then addition to the terminal oxygen atom of the peroxy end forming a new $\mathrm{O}-\mathrm{O}$ bond to give a trioxide, $\mathrm{ROOOH}$. The formation of this trioxide is exothermic by $31.33 \mathrm{kcal} \mathrm{mol}^{-1}$ in terms of $\Delta H_{298 \mathrm{~K}}$ (see Table 1). Seen from Fig. 1, the energy barrier of ${ }^{1}$ TSA is computed to be -3.64 kcal $\mathrm{mol}^{-1}$ with respect to the ${ }^{1} \mathrm{RC} 1$ and the reactants, respectively, which is much lower than the energy barrier of ${ }^{1} \mathrm{TS} 1\left(-0.46 \mathrm{kcal} \mathrm{mol}^{-1}\right)$ or ${ }^{3} \mathrm{TS} 1\left(-1.19 \mathrm{kcal} \mathrm{mol}^{-1}\right)$.

\subsection{OH-adduct formation between 1,3,5-TMB BPR and OH}

As the 1,3,5-TMB BPR contains a double bond in the ring, the reaction of $\mathrm{OH}$ addition to the double bond producing $\mathrm{OH}$ adduct should also be considered. Due to the substitution of the $\mathrm{O}_{2}$-bridged group in 1,3,5-TMB $\mathrm{BPR}$, the $\mathrm{OH}$ addition on the 


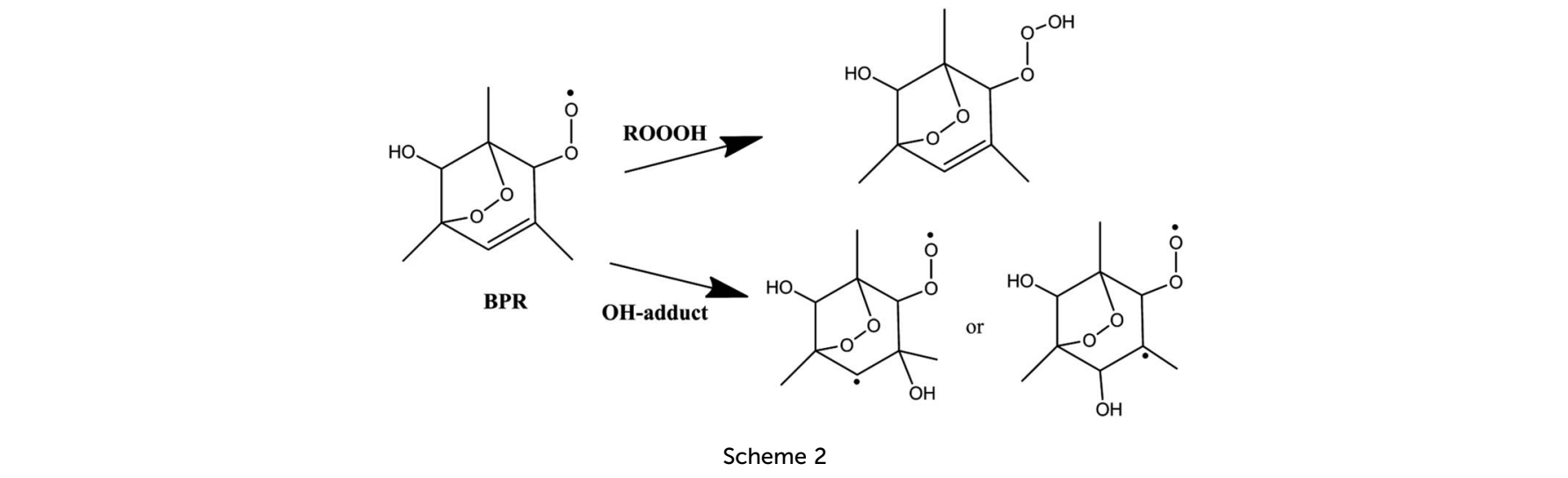<smiles>CC1=CC2(C)OOC1(C)C(O)C2O</smiles>

BPR

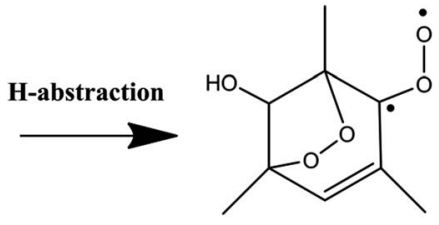

CI
Scheme 3

$\mathrm{C}=\mathrm{C}$ bond proceeds through a reactant complex $\left({ }^{3} \mathrm{RC} 2\right)$ by strong hydrogen bond interactions between the $\mathrm{H}$ from the $\mathrm{OH}$ radical and the $\mathrm{O}$ from the $\mathrm{O}_{2}$-bridged group (see Fig. 1 and 2).
The distances of the hydrogen bonds are $2.066 \AA$ and $2.420 \AA$, and the binding energy of ${ }^{3} \mathrm{RC} 2$ is $-7.47 \mathrm{kcal} \mathrm{mol}^{-1}$. Then the reaction continues by addition of the $\mathrm{OH}$ radical to either of the carbon atoms of the double bond through the triplet transition states ${ }^{3}$ TSA 1 and ${ }^{3}$ TSA2. Due to this addition, the $\mathrm{OH}$-adduct 1 is formed by a shortening of $\mathrm{C} \cdots \mathrm{OH}$ bond from $2.060 \AA$ in ${ }^{3} \mathrm{TSA} 1$ to $1.427 \AA$, simultaneously, the $\mathrm{C}=\mathrm{C}$ bond length is elongated from $1.358 \AA$ in ${ }^{3}$ TSA 1 to $1.496 \AA$ in the product $\mathrm{OH}$-adduct 1 . Similarly, the $\mathrm{OH}$-adduct 2 is formed by a shortening of $\mathrm{C} \cdots \mathrm{OH}$ bond from $2.062 \AA$ in ${ }^{3} \mathrm{TSA} 2$ to $1.414 \AA$, at the same time, the $\mathrm{C}=\mathrm{C}$ bond length is elongated from $1.356 \AA$ in ${ }^{3} \mathrm{TSA} 2$ to $1.497 \AA$ in the product $\mathrm{OH}$-adduct 2 . The formation of $\mathrm{OH}$-adduct 1 and $\mathrm{OH}$-adduct 2 are exothermic by 32.52 and $34.91 \mathrm{kcal} \mathrm{mol}^{-1}$

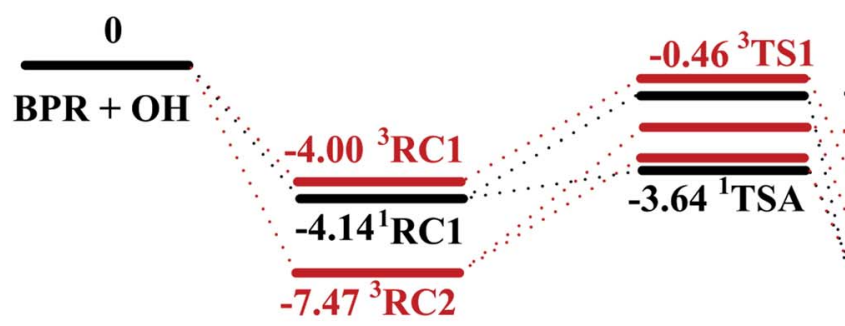

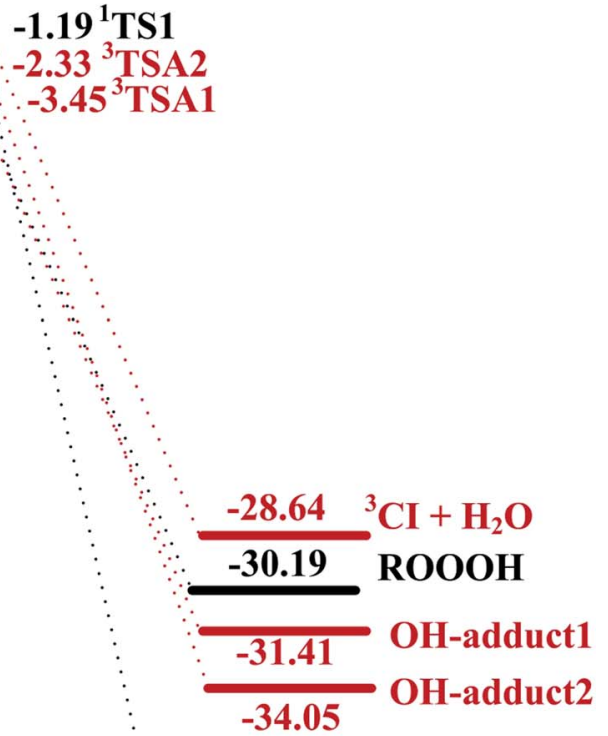

$-34.05$

Fig. 1 Potential energy surface for BPR + OH biradical reactions. The energies $\left(\mathrm{kcal} \mathrm{mol}^{-1}\right)$ relative to separated reactants $\mathrm{BPR}$ and $\mathrm{OH}$ at $\mathrm{MO}$ $\mathrm{HX} / 6-311+\mathrm{g}(2 \mathrm{df}, 2 \mathrm{p})$ level of theory. $\mathrm{RC}$, reactant complex; TS, transition state; $\mathrm{Cl}$, Criegee intermediate. The singlet reaction pathways are depicted in black, and the triplet reaction pathways are depicted in red for clarity. 

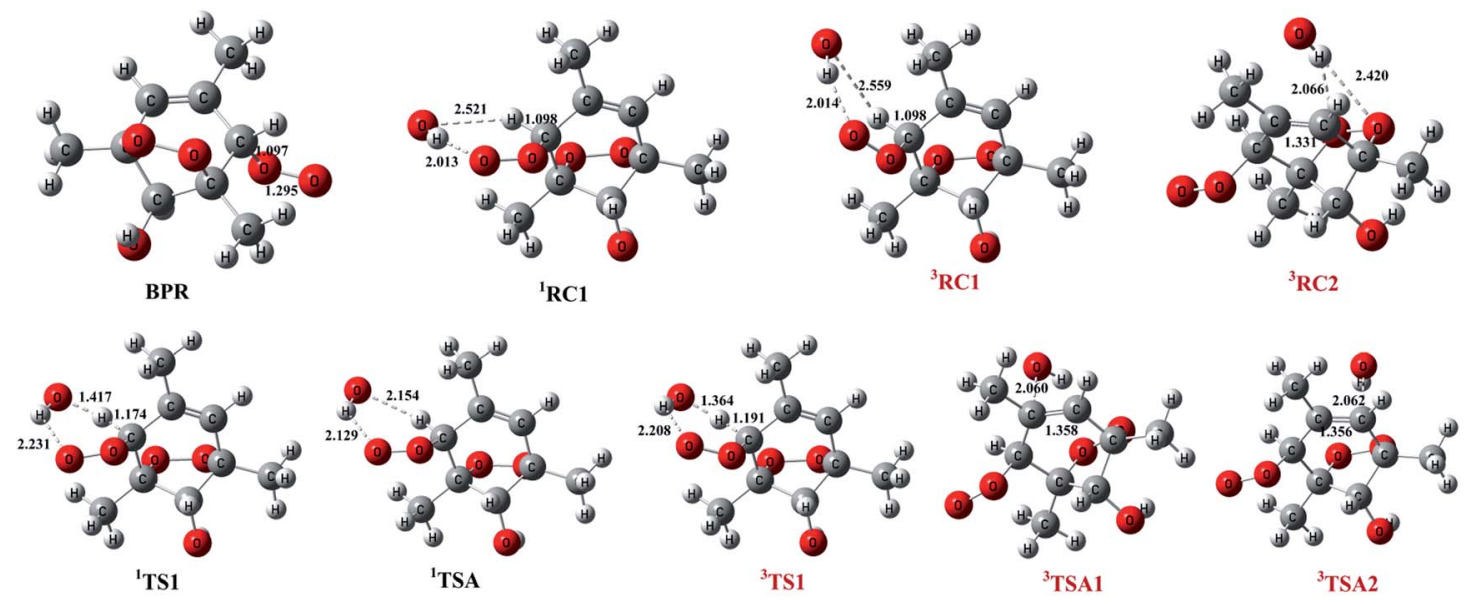

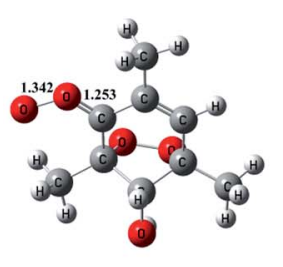

${ }^{1} \mathrm{CI}$

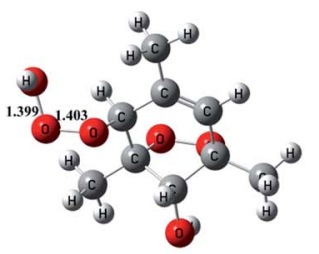

ROOOH

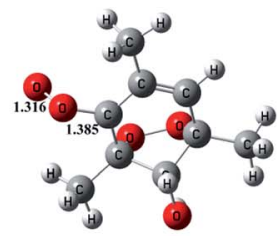

${ }^{3} \mathrm{CI}$

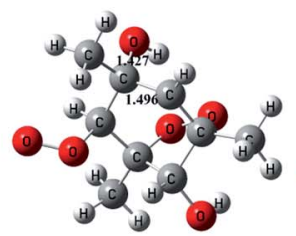

OH-adduct1

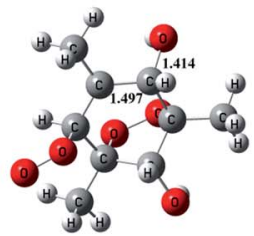

OH-adduct2

Fig. 2 Structures of key species in the reaction of bicyclic peroxy radical (BPR) with OH optimized at M08-HX/6-311 + g(2df,2p) level of theory. The singlet species are named in black, while the triplet ones are named in red for clarity. Bond distances are in angstrom.

respectively in terms of $\Delta H_{298} \mathrm{~K}$ (see Table 1). The energy barriers of ${ }^{3}$ TSA1 and ${ }^{3}$ TSA2 are $-3.45 \mathrm{kcal}^{\mathrm{mol}}{ }^{-1}$ and $-2.33 \mathrm{kcal} \mathrm{mol}^{-1}$ respectively, which are also lower than that of ${ }^{1} \mathrm{TS} 1$ or ${ }^{3} \mathrm{TS} 1$, indicating that $\mathrm{OH}$ addition reactions including the formation of $\mathrm{ROOOH}$ and $\mathrm{OH}$-adducts are the dominant pathways. This conclusion can be supported by the study of kinetics in the following section.

\subsection{Criegee intermediate formation between 1,3,5-TMB BPR and $\mathrm{OH}$}

The hydrogen abstraction reaction of 1,3,5-TMB bicyclic peroxy radical with $\mathrm{OH}$ to form Criegee intermediate can occur via both singlet and triplet potential energy surfaces (PESs). On the singlet PES, as shown in Fig. 1, the $\mathrm{H}$-abstraction pathway starts with the reactant complex ${ }^{1} \mathrm{RC} 1$. Thereafter, ${ }^{1} \mathrm{RC} 1$ is transformed into ${ }^{1} \mathrm{CI}$ and water through a transition state ${ }^{1} \mathrm{TS} 1$ with the energy barrier of $-1.19 \mathrm{kcal} \mathrm{mol}^{-1}$ (with respect to the reactants). In ${ }^{1} \mathrm{TS} 1$, the $\mathrm{C}-\mathrm{H}$ bond is breaking with the distance of $1.174 \AA$. Simultaneously, the $\mathrm{H}$ atom is abstracted by the $\mathrm{O}$ atom from $\mathrm{OH}$ with the bond length of $1.417 \AA$. In addition, this reaction producing singlet $\mathrm{CI}\left({ }^{1} \mathrm{CI}\right)$ is significantly exothermic $\left(\Delta H_{298 \mathrm{~K}}=-46.19 \mathrm{kcal} \mathrm{mol}^{-1}\right.$, see Table 1$)$. The H-abstraction mechanism is also found on the triplet PES. As shown in Fig. 1, the initial step is formation of a reactant complex ${ }^{3} \mathrm{RC} 1$ stabilized by $4.00 \mathrm{kcal} \mathrm{mol}^{-1}$ with respect to the reactants. As seen from Fig. 2, the ${ }^{3} \mathrm{RC} 1$ is characterized by H-bond interaction with the bond length of $2.014 \AA$ between the hydrogen atom of $\mathrm{OH}$ and the terminal oxygen atom of BPR. Then the $\mathrm{H}$ atom of $\mathrm{BPR}$ is abstracted by $\mathrm{OH}$ radical, leading to the formation of ${ }^{3} \mathrm{CI}$ $+\mathrm{H}_{2} \mathrm{O}$ via ${ }^{3} \mathrm{TS} 1$. This transition state ${ }^{3} \mathrm{TS} 1$ is lower located than the reactants by $0.46 \mathrm{kcal} \mathrm{mol}^{-1}$ which involves a shortening of $\mathrm{H} \cdots \mathrm{OH}$ bond (from 2.559 to $1.364 \AA$ ) and an elongation of the C-H bond (from 1.098 to $1.191 \AA$ ) which will eventually break. Additionally, this reaction producing triplet $\mathrm{CI}\left({ }^{3} \mathrm{CI}\right)$ is moderately exothermic $\left(\Delta H_{298 \mathrm{~K}}=-28.09 \mathrm{kcal} \mathrm{mol}^{-1}\right.$, see Table 1$)$.

As seen from Fig. 2, the singlet ${ }^{1} \mathrm{RC} 1$ and triplet ${ }^{3} \mathrm{RC} 1$, as well as the corresponding ${ }^{1} \mathrm{TS} 1$ and triplet ${ }^{3} \mathrm{TS} 1$ all show sixmembered ring forms though there are some structural discrepancies in the reactant complexes and transition states. The energy barrier of ${ }^{1} \mathrm{TS} 1$ and ${ }^{3} \mathrm{TS} 1$ differs by $0.73 \mathrm{kcal} \mathrm{mol}^{-1}$,

Table 1 Relative energies $\left(\Delta(E+Z P E)\right.$ and $\Delta E_{298}$ K $)$, enthalpies $\left(\Delta H_{298}\right.$ K), and Gibbs free energies $\left(\Delta G_{298} \mathrm{k}\right)$ for the BPR $+\mathrm{OH}$ reaction. All energies are calculated relative to the energy of $\mathrm{BPR}+\mathrm{OH}$, in units of $\mathrm{kcal} \mathrm{mol}^{-1}$, at the M08-HX/6-311 + g(2df,2p) level of theory

\begin{tabular}{lllll}
\hline Compound & $\Delta(E+\mathrm{ZPE})$ & $\Delta E_{298 \mathrm{~K}}$ & $\Delta H_{298 \mathrm{~K}}$ & $\Delta G_{298 \mathrm{~K}}$ \\
\hline $\mathrm{BPR}+\mathrm{OH}$ & 0 & 0 & 0 & 0 \\
${ }^{1} \mathrm{RC} 1$ & -4.14 & -3.92 & -4.51 & 4.53 \\
${ }^{1} \mathrm{TS} 1$ & -1.19 & -1.44 & -2.04 & 8.30 \\
${ }^{1} \mathrm{CI}+\mathrm{H}_{2} \mathrm{O}$ & -46.21 & -46.19 & -46.19 & -45.86 \\
${ }^{1} \mathrm{TSA}$ & -3.64 & -3.77 & -4.36 & 5.65 \\
$\mathrm{ROOOH}$ & -30.19 & -30.74 & -31.33 & -20.17 \\
${ }^{3} \mathrm{RC} 1$ & -4.00 & -3.85 & -4.44 & 4.10 \\
${ }^{3} \mathrm{TS} 1$ & -0.46 & -0.65 & -1.24 & 8.19 \\
${ }^{3} \mathrm{CI}+\mathrm{H}_{2} \mathrm{O}$ & -28.64 & -28.09 & -28.09 & -30.01 \\
${ }^{3} \mathrm{RC} 2$ & -7.47 & -7.15 & -7.74 & 0.60 \\
${ }^{3} \mathrm{TSA} 1$ & -3.45 & -3.82 & -4.41 & 5.77 \\
OH-adduct 1 & -31.41 & -31.93 & -32.52 & -21.84 \\
${ }^{3} \mathrm{TSA} 2$ & -2.33 & -2.58 & -3.17 & 6.48 \\
OH-adduct 2 & -34.05 & -34.32 & -34.91 & -25.62
\end{tabular}


Table 2 Calculated values at $298 \mathrm{~K}$ of equilibrium constants $\left(K_{\text {eq }}, \mathrm{cm}^{3} \mathrm{~mol}^{-1}\right)$, the Eckart tunneling correction $(\kappa)$, unimolecular rate constants $\left(k_{2}\right.$, $\left.\mathrm{s}^{-1}\right)$ including tunneling correction, rate constants $\left(k_{\mathrm{TS}}, \mathrm{cm}^{3} \mathrm{~mol}^{-1} \mathrm{~s}^{-1}\right)$, and the overall rate constant $k_{\text {Total }}\left(k_{\mathrm{Total}}=k^{1} \mathrm{TS}_{\mathrm{T} 1}+k^{1}{ }_{\mathrm{TSA}}+k^{3} \mathrm{TS} 1+k^{3} \mathrm{TSA}_{1}+\right.$ ${ }^{3} \mathrm{TSA} 2, \mathrm{~cm}^{3} \mathrm{~mol}^{-1} \mathrm{~s}^{-1}$ )

\begin{tabular}{lllll}
\hline Reaction pathways & $K_{\text {eq }}$ & $\kappa$ & $k_{2}$ & $k_{\text {TS }}$ \\
\hline${ }^{1}$ TS1 & $1.95 \times 10^{-23}$ & 2.10 & $2.23 \times 10^{10}$ & $4.35 \times 10^{-13}$ \\
${ }^{1}$ TSA & $1.95 \times 10^{-23}$ & 1.02 & $9.62 \times 10^{11}$ & $1.88 \times 10^{-11}$ \\
${ }^{3}$ TS1 & $4.02 \times 10^{-23}$ & 2.52 & $1.57 \times 10^{10}$ & $6.31 \times 10^{-13}$ \\
${ }^{3}$ TSA1 & $1.49 \times 10^{-20}$ & 1.56 & $1.55 \times 10^{9}$ & $2.31 \times 10^{-11}$ \\
${ }^{3}$ TSA2 & $1.49 \times 10^{-20}$ & 1.60 & $4.81 \times 10^{8}$ & $7.17 \times 10^{-12}$
\end{tabular}

indicating that, for the hydrogen abstraction mechanism, the reaction rate of singlet Criegee intermediate ${ }^{1} \mathrm{CI}$ formation is close to that of triplet ${ }^{3} \mathrm{CI}$ formation.

\subsection{Kinetics}

It has been shown that either $\mathrm{OH}$ addition or $\mathrm{H}$-abstraction pathway consists of a reversible first step involving the barrierless formation of a reactant complex (RC), followed by the irreversible formation of products. Therefore, the reaction pathway is a two-step process as described by Scheme 4, where the reactant complex is in equilibrium with the reactants.

If $k_{1}$ and $k_{-1}$ are the rate constants for the first step and $k_{2}$ is the rate constant for the second, a steady-state analysis leads to a rate constant for the reaction pathway under consideration, which can be approximated as

$$
k=\frac{k_{1}}{k_{-1}} k_{2}=K_{\mathrm{eq}} k_{2}
$$

where $K_{\text {eq }}$ stands for the equilibrium constant in the first step, which can be written as

$$
K_{\text {eq }}=\frac{Q_{\mathrm{RC}}}{Q_{\mathrm{R}}} \mathrm{e}^{-\left(E_{\mathrm{RC}}-E_{\mathrm{R}}\right) /(\mathrm{RT})}
$$

According to the conventional transition state theory, the unimolecular rate constant $k_{2}$ with the Eckart tunneling correction is given by

$$
k_{2}=\sigma \kappa \frac{k_{\mathrm{B}} T}{h} \frac{Q_{\mathrm{TS}}^{\neq}}{Q_{\mathrm{RC}}} \mathrm{e}^{-\left(E_{\mathrm{TS}}-E_{\mathrm{RC}}\right) /(\mathrm{RT})}
$$

where $Q_{\mathrm{TS}}^{\neq}, Q_{\mathrm{R}}$ and $Q_{\mathrm{RC}}$ are partition functions of the transition state, the reactants and the reactant complex, $\sigma$ is the symmetry factor, $\kappa$ is the tunneling factor, $k_{\mathrm{B}}$ is the Boltzmann's constant, and $h$ is Planck's constant. The $E_{\mathrm{TS}}, E_{\mathrm{R}}$ and $E_{\mathrm{RC}}$ are the total energy inclusion ZPE correction of the transition state, the reactants and the reactant complex.

The rate coefficients were calculated using the M08-HX/6-311 $+\mathrm{g}(2 \mathrm{df}, 2 \mathrm{p})$ optimized geometrical parameters, frequencies and

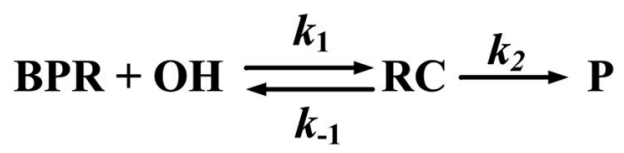

Scheme 4 energies listed in Table 2. From Table 2, the rate constants of $\mathrm{OH}$ addition reactions by ${ }^{1} \mathrm{TSA},{ }^{3} \mathrm{TSA} 1$ and ${ }^{3} \mathrm{TSA} 2$ are computed to be $1.88 \times 10^{-11} \mathrm{~cm}^{3} \mathrm{~mol}^{-1} \mathrm{~s}^{-1}, 2.31 \times 10^{-11} \mathrm{~cm}^{3} \mathrm{~mol}^{-1} \mathrm{~s}^{-1}$, and $7.17 \times 10^{-12} \mathrm{~cm}^{3} \mathrm{~mol}^{-1} \mathrm{~s}^{-1}$ respectively. While the rate constants of $\mathrm{H}$-abstractions via singlet ${ }^{1} \mathrm{TS} 1$ and triplet ${ }^{3} \mathrm{TS} 1$ at $298 \mathrm{~K}$ are $4.35 \times 10^{-13} \mathrm{~cm}^{3} \mathrm{~mol}^{-1} \mathrm{~s}^{-1}$ and $6.31 \times 10^{-13} \mathrm{~cm}^{3}$ $\mathrm{mol}^{-1} \mathrm{~s}^{-1}$ respectively. The computed overall rate constant is $5.01 \times 10^{-11} \mathrm{~cm}^{3} \mathrm{~mol}^{-1} \mathrm{~s}^{-1}$. The atmospheric lifetime of the studied 1,3,5-trimethylbenzene bicyclic peroxy radical due to reaction with $\mathrm{OH}$ can be estimated to be 5.54 hour using the following expression: $\tau=1 /(k[\mathrm{X}])$, where $\mathrm{X}$ is the average concentration of $\mathrm{OH}$ in the atmosphere $\left([\mathrm{OH}]=1.0 \times 10^{6}\right.$ molecules per $\left.\mathrm{cm}^{-3}\right) .{ }^{39}$ The branching ratios for $\mathrm{H}$-abstraction pathways via ${ }^{1}$ TS1 and ${ }^{3}$ TS1 are only $8.68 \times 10^{-3}$ and $1.26 \times$ $10^{-2}$ respectively. Hence the $\mathrm{OH}$ addition reactions including the formation of $\mathrm{ROOOH}$ and $\mathrm{OH}$-adducts are the major paths in contrast with $\mathrm{H}$-abstraction channels producing Criegee intermediate which are negligible. The degradation of the $\mathrm{ROOOH}$ species in the atmosphere is significant which might help explain the difference in simulated and observed $\mathrm{OH}$ concentrations under low NOx environment. ${ }^{40}$ The $\mathrm{OH}$-adducts may contribute to the formation and growth of SOA through subsequent reactions. Therefore, research is urgently needed into the atmospheric fate and possible influence of the 1,3,5TMB ROOOH and $\mathrm{OH}$-adducts on atmospheric chemistry.

\section{Conclusions}

In the present study, the mechanism and kinetics of the atmospheric reaction of 1,3,5-TMB bicyclic peroxy radical with $\mathrm{OH}$ have been studied by M08-HX/6-311 + g(2df,2p) method and CTST including Eckart tunneling correction. The conclusions are drawn in the following:

(1) Two types of mechanisms including $\mathrm{OH}$ addition producing $\mathrm{ROOOH}$ and $\mathrm{OH}$-adducts, and $\mathrm{H}$-abstraction for Criegee intermediate formation are considered. Both the $\mathrm{OH}$ addition to the peroxy end and to the double bond of 1,3,5-TMB bicyclic peroxy radical are easier than $\mathrm{H}$-abstraction reaction due to the lower energy barrier.

(2) The rate constants of $\mathrm{OH}$ addition to BPR are computed to be $1.88 \times 10^{-11} \mathrm{~cm}^{3} \mathrm{~mol}^{-1} \mathrm{~s}^{-1}, 2.31 \times 10^{-11} \mathrm{~cm}^{3} \mathrm{~mol}^{-1} \mathrm{~s}^{-1}$, and $7.17 \times 10^{-12} \mathrm{~cm}^{3} \mathrm{~mol}^{-1} \mathrm{~s}^{-1}$ by ${ }^{1} \mathrm{TSA},{ }^{3} \mathrm{TSA} 1$ and ${ }^{3} \mathrm{TSA} 2$ respectively, while the abstraction rate constants via ${ }^{1}$ TS1 and ${ }^{3} \mathrm{TS} 1$ are calculated to be $4.35 \times 10^{-13} \mathrm{~cm}^{3} \mathrm{~mol}^{-1} \mathrm{~s}^{-1}$ and $6.31 \times 10^{-13}$ $\mathrm{cm}^{3} \mathrm{~mol}^{-1} \mathrm{~s}^{-1}$ respectively at $298 \mathrm{~K}$. Kinetically, the abstraction 
reactions are much less favorable than $\mathrm{OH}$-addition reactions, thus can be negligible.

(3) The 1,3,5-TMB ROOOH and OH-adducts are the most dominant products. The atmospheric fate and possible influence of the $\mathrm{ROOOH}$ and $\mathrm{OH}$-adducts on atmospheric chemistry have not been explored yet.

\section{Conflicts of interest}

There are no conflicts to declare.

\section{Acknowledgements}

We would like to thank financial support from the National Natural Science Foundation of China (41605102, 91544228, $41575125,21876177,41775125)$, the National Key Research and Development Program of China (2016YFC0202205, 2017YFC0209401), the Youth Innovation Promotion Association CAS (2019439), and the Science and Technology Foundation of Guizhou Province, China ([2019]5648 and [2018]1080).

\section{References}

1 R. G. Derwent, T. J. Davies, M. Delaney, G. J. Dollard, R. A. Field, P. Dumitrean, P. D. Nason, B. M. R. Jones and S. A. Pepler, Atmos. Environ., 2000, 34, 297-312.

2 L. T. Molina, C. E. Kolb, B. de Foy, B. K. Lamb, W. H. Brune, J. L. Jimenez, R. Ramos-Villegas, J. Sarmiento, V. H. ParamoFigueroa, B. Cardenas, V. Gutierrez-Avedoy and M. J. Molina, Atmos. Chem. Phys., 2007, 7, 2447-2473.

3 E. Velasco, B. Lamb, H. Westberg, E. Allwine, G. Sosa, J. L. Arriaga-Colina, B. T. Jobson, M. L. Alexander, P. Prazeller, W. B. Knighton, T. M. Rogers, M. Grutter, S. C. Herndon, C. E. Kolb, M. Zavala, B. de Foy, R. Volkamer, L. T. Molina and M. J. Molina, Atmos. Chem. Phys., 2008, 7, 329-353.

4 A. Metzger, J. Dommen, K. Gaeggeler, J. Duplissy, A. S. H. Prevot, J. Kleffmann, Y. Elshorbany, A. Wisthaler and U. Baltensperger, Atmos. Chem. Phys., 2008, 8, 64536468.

5 M. J. Elrod, J. Phys. Chem. A, 2011, 115, 8125-8130.

6 K. P. Wyche, P. S. Monks, A. M. Ellis, R. L. Cordell, A. E. Parker, C. Whyte, A. Metzger, J. Dommen, J. Duplissy, A. S. H. Prevot, U. Baltensperger, A. R. Rickard and F. Wulfert, Atmos. Chem. Phys., 2009, 9, 635-665.

7 M. E. Jenkin and K. C. Clemitshaw, Atmos. Environ., 2000, 34, 2499-2527.

8 J. J. Orlando and G. S. Tyndall, Chem. Soc. Rev., 2012, 41, 6294-6317.

9 J. A. Thornton, P. J. Wooldridge, R. C. Cohen, M. Martinez, H. Harder, W. H. Brune, E. J. Williams, J. M. Roberts, F. C. Fehsenfeld, S. R. Hall, R. E. Shetter, B. P. Wert and A. Fried, J. Geophys. Res., 2002, 107, ACH 7-1-ACH 7-17.

10 E. Assaf, B. Song, A. Tomas, C. Schoemaecker and C. Fittschen, J. Phys. Chem. A, 2016, 120, 8923-8932.

11 E. Assaf, S. Tanaka, Y. Kajii, C. Schoemaecker and C. Fittschen, Chem. Phys. Lett., 2017, 684, 245-249.
12 A. Bossolasco, E. P. Faragó, C. Schoemaecker and C. Fittschen, Chem. Phys. Lett., 2014, 593, 7-13.

13 E. P. Faragó, C. Schoemaecker, B. Viskolcz and C. Fittschen, Chem. Phys. Lett., 2015, 619, 196-200.

14 C. Yan, S. Kocevska and L. N. Krasnoperov, J. Phys. Chem. A, 2016, 120, 6111-6121.

15 A. T. Archibald, A. S. Petit, C. J. Percival, J. N. Harvey and D. E. Shallcross, Atmos. Sci. Lett., 2009, 10, 102-108.

16 C. Fittschen, L. K. Whalley and D. E. Heard, Environ. Sci. Technol., 2014, 48, 7700-7701.

17 E. Assaf, L. Sheps, L. Whalley, D. Heard, A. Tomas, C. Schoemaecker and C. Fittschen, Environ. Sci. Technol., 2017, 51, 2170-2177.

18 J. F. Müller, Z. Liu, V. S. Nguyen, T. Stavrakou, J. N. Harvey and J. Peeters, Nat. Commun., 2016, 7, 13213.

19 B. Long, J. L. Bao and D. G. Truhlar, J. Am. Chem. Soc., 2016, 138, 14409-14422.

20 B. Long, J. L. Bao and D. G. Truhlar, Proc. Natl. Acad. Sci. U. S. A., 2018, 115, 6135-6140.

21 B. Long, J. L. Bao and D. G. Truhlar, J. Am. Chem. Soc., 2019, 141, 611-617.

22 M. Altarawneh, E. M. Kennedy, B. Z. Dlugogorski and J. C. Mackie, J. Phys. Chem. A, 2008, 112, 6960-6967.

23 T. J. Frankcombe, J. Phys. Chem. A, 2008, 112, 1572-1575.

24 J. M. Andino, J. N. Smith, R. C. Flagan, W. A. Goddard and J. H. Seinfeld, J. Phys. Chem., 1996, 100, 10967-10980.

25 Y. Zhao and D. G. Truhlar, J. Chem. Theory Comput., 2008, 4, 1849-1868.

26 X. F. Xu, I. M. Alecu and D. G. Truhlar, J. Chem. Theory Comput., 2011, 7, 1667-1676.

27 C. Gonzalez and H. B. Schlegel, J. Phys. Chem., 1989, 90, 2154-2161.

28 C. Gonzalez and H. B. Schlegel, J. Phys. Chem., 1990, 94, 5523-5527.

29 M. J. Frisch, G. W. Trucks, H. B. Schlegel, G. E. Scuseria, M. A. Robb, J. R. Cheeseman, G. Scalmani, V. Barone, G. A. Petersson, H. Nakatsuji, X. Li, M. Caricato, A. V. Marenich, J. Bloino, B. G. Janesko, R. Gomperts, B. Mennucci, H. P. Hratchian, J. V. Ortiz, A. F. Izmaylov, J. L. Sonnenberg, D. Williams-Young, F. Ding, F. Lipparini, F. Egidi, J. Goings, B. Peng, A. Petrone, T. Henderson, D. Ranasinghe, V. G. Zakrzewski, J. Gao, N. Rega, G. Zheng, W. Liang, M. Hada, M. Ehara, K. Toyota, R. Fukuda, J. Hasegawa, M. Ishida, T. Nakajima, Y. Honda, O. Kitao, H. Nakai, T. Vreven, K. Throssell, J. A. Montgomery Jr, J. E. Peralta, F. Ogliaro, M. J. Bearpark, J. J. Heyd, E. N. Brothers, K. N. Kudin, V. N. Staroverov, T. A. Keith, R. Kobayashi, J. Normand, K. Raghavachari, A. P. Rendell, J. C. Burant, S. S. Iyengar, J. Tomasi, M. Cossi, J. M. Millam, M. Klene, C. Adamo, R. Cammi, J. W. Ochterski, R. L. Martin, K. Morokuma, O. Farkas, J. B. Foresman, and D. J. Fox, Gaussian 16, Revision A.03, Gaussian, Inc., Wallingford CT, 2016.

30 M. G. Evans and M. Polanyi, Trans. Faraday Soc., 1935, 31, 875-894.

31 H. Eyring, J. Chem. Phys., 1935, 3, 107-115. 
32 D. G. Truhlar, B. C. Garrett and S. J. Klippenstein, J. Phys. Chem., 1996, 100, 12771-12800.

33 C. Eckart, Phys. Rev., 1930, 35, 1303-1309.

34 W. T. Duncan, R. L. Bell and T. N. Truong, J. Comput. Chem., 1998, 19, 1039-1052.

35 S. Zhang and T. N. Truong, VKLab, version 1.0. University of Utah: Salt Lake City, UT, 2001.

36 E. Assaf, C. Schoemaecker, L. Vereecken and C. Fittschen, Int. J. Chem. Kinet., 2018, 50, 670-680.
37 M. A. H. Khan, C. J. Percival, R. L. Caravan, C. A. Taatjesc and D. E. Shallcross, Environ. Sci.: Processes Impacts, 2018, 20, 437-453.

38 D. Osborn and C. A. Taatjes, Int. Rev. Phys. Chem., 2015, 34, 309-360.

39 W. J. Bloss, M. J. Evans, J. D. Lee, R. Sommariva, D. E. Heard and M. J. Pilling, Faraday Discuss., 2005, 130, 425-436.

40 C. Fittschen, M. A. Ajami, S. Batut, V. Ferracci, S. ArcherNicholls, A. T. Archibald and C. Schoemaecker, Atmos. Chem. Phys., 2019, 19, 349-362. 